\title{
Leukocytoclastic vasculitis in patients with IL12B or IL12RB1 deficiency: case report and review of the literature
}

Niusha Sharifinejad ${ }^{1}$, Seyed Alireza Mahdaviani ${ }^{2 *}$ (D, Mahnaz Jamee ${ }^{3,4}$, Zahra Daneshmandi ${ }^{2}$, Afshin Moniri ${ }^{5}$, Majid Marjani ${ }^{5}$, Payam Tabarsi ${ }^{5}$, Parisa Farnia ${ }^{6}$, Mahsa Rekabi ${ }^{2}$, Mazdak Fallahi ${ }^{2}$,

Seyedeh Atefeh Hashemimoghaddam², Masoumeh Mohkam³, Jacinta Bustamante ${ }^{7,8,9}$, Jean-Laurent Casanova ${ }^{7,8,10}$,

Davood Mansouri ${ }^{2}$ and Ali Akbar Velayati ${ }^{2}$

\begin{abstract}
Background: Mendelian susceptibility to mycobacterial disease (MSMD) is an inborn error of immunity, resulting in susceptibility to weakly virulent mycobacteria and other intramacrophagic pathogens. Rheumatologic manifestations and vasculitis are considered rare manifestations in MSMD patients.

Case presentation: In this study, we reported a 20-year-old female who was presented with recurrent lymphadenitis following bacillus Calmette-Guérin (BCG) vaccination and a history of recurrent disseminated rash diagnosed as leukocytoclastic vasculitis (LCV). A slight reduction in lymphocyte subsets including CD4+, CD19+, and CD $16+56$ T-cell count, as well as an elevation in immunoglobulins level (IgG, $\lg A$, $\operatorname{lgM}$, $\lg E)$, were observed in the patient. Whole exome sequencing revealed a homozygous Indel-frameshift mutation, c.527_528delCT ( $p$. S176Cfs*12), at the exon 5 of the $I L 12 B$ gene. She experienced symptom resolution after treatment with antimycobacterial agents and subcutaneous IFN- $\gamma$. We conducted a manual literature search for MSMD patients reported with vasculitis in PubMed, Web of Science, and Scopus databases. A total of 18 MSMD patients were found to be affected by a variety of vasculitis phenotypes mainly including LCV and Henoch-Schönlein purpura (HSP) with often skin involvement. Patients were all involved with vasculitis at the median age of 6.8 (2.6-7.7) years, nearly 6.1 years after the initial presentations. Sixteen patients (88.9\%) had IL12RBI defects and concurrent Salmonella infection was reported in 15 (88.2\%) patients.

Conclusion: The lack of IL-12 and IL-23 signaling/activity/function and salmonella infection may be triggering factors for the development of leukocytoclastic vasculitis. IL12B or IL12RB1 deficiency and salmonellosis should be considered in MSMD patients with vasculitis.
\end{abstract}

Keywords: Primary immunodeficiency, Mendelian susceptibility to mycobacterial disease, MSMD, Vasculitis, IL12RB

\footnotetext{
* Correspondence: mahdaviani@sbmu.ac.ir

${ }^{2}$ Pediatric Respiratory Diseases Research Center, National Research Institute of

Tuberculosis and Lung Diseases (NRITLD), Shahid Beheshti University of Medical Sciences, Tehran, Iran

Full list of author information is available at the end of the article
}

(c) The Author(s). 2021 Open Access This article is licensed under a Creative Commons Attribution 4.0 International License, which permits use, sharing, adaptation, distribution and reproduction in any medium or format, as long as you give appropriate credit to the original author(s) and the source, provide a link to the Creative Commons licence, and indicate if changes were made. The images or other third party material in this article are included in the article's Creative Commons licence, unless indicated otherwise in a credit line to the material. If material is not included in the article's Creative Commons licence and your intended use is not permitted by statutory regulation or exceeds the permitted use, you will need to obtain permission directly from the copyright holder. To view a copy of this licence, visit http://creativecommons.org/licenses/by/4.0/ The Creative Commons Public Domain Dedication waiver (http://creativecommons.org/publicdomain/zero/1.0/) applies to the data made available in this article, unless otherwise stated in a credit line to the data. 


\section{Background}

Mendelian susceptibility to mycobacterial disease (MSMD) is a rare group of human inborn error of immunity (IEI) characterized by selective susceptibility to weakly virulent mycobacteria in otherwise healthy subjects, without overt immunological abnormalities [1]. Mycobacterial involvements may have a broad spectrum of clinical manifestations, from localized to disseminated, and acute to chronic infections. Although MSMD patients typically have normal resistance against other microbes, a number of viral infections, particularly herpes virus, bacterial, fungal, and parasitic infections have also been reported in patients with some underlying genetic defects [2]. Some MSMD patients are also particularly susceptible to Salmonella spp and develop a wide spectrum of clinical diseases, ranging from gastroenteritis to bacteremia [2-4]. Standard immunological tests for IEIs are generally normal in patients with MSMD [5]. Seventeen gene mutations are involved in MSMD (IL12B, IL12RB1, IL12RB2, IL23R, JAK1, RORC, ISG15, TYK2, IRF8, SPPL2A, CYBB, IFNGR1, IFNGR2, STAT1, NEMO, TBX21, and ZNFX1) $[2,5-7]$. These genes are generally in the pathway of interferon gamma (IFN- $\gamma$ ), which is the macrophage-activating factor involved in anti-mycobacterium defense [8]. Leukocytoclastic vasculitis (LCV) is an immune complex mediated disease affecting small vessels of the skin and can be connected with drugs or be found as a component of other diseases, such as infections, connective tissue disorders, and malignancies [9]. LCV is considered a novel manifestation in MSMD patients and is mainly connected to microbial agents [10]. Biallelic mutations of IL12RB1 are the most frequent genetic defect causing MSMD, and are found in about $60 \%$ of diagnosed patients [11]. In addition to the receptor for interleukin (IL)-12, IL-23 is also composed of IL-12R $\beta 1$ and IL-23R subunits [12]. Therefore, patients with IL-12R $\beta 1$ deficiency suffer from mycobacterial diseases due to IL12R and IL23R deficiencies, and chronic mucocutaneous candidiasis (CMC) due to impaired IL-23-dependent IL-17 production, while the etiology of salmonellosis like mycobacteriosis probably involves both IL12R and IL23R deficiencies given the relative rarity of salmonellosis in other MSMD etiologies [13]. Of note, IL-12 is involved in the generation of T helper (Th) 1 responses and production of IFN- $\gamma$ [14], also, Th1 promotes immune responses against Salmonella species [15]. In this study, we identified a homozygous Indel frameshift mutation at the $I L 12 B$ gene in a patient with recurrent lymphadenitis and leukocytoclastic vasculitis. We also reviewed the literature of MSMD cases presenting vasculitis.

\section{Methods}

Patient information including demographic data, medical history, and physical examination, were collected by direct interviews and examining the patient's clinical record based on national consensus on diagnosis and management guidelines for primary immunodeficiency [16]. Demographic data included age, gender, age at disease onset, age of diagnosis, and delay of diagnosis. The recorded laboratory data were: complete cell blood counts, T- and B-cells subsets (assessed using flow cytometry analysis), and serum levels of immunoglobulins and autoantibodies (assessed using nephelometry and enzyme-linked immunosorbent assay). Medical information was collected after obtaining written informed consent from the patient and his parents, following the principles of the ethics committee of the Shahid Beheshti University of Medical Sciences. Secondary causes of vasculitis were excluded by history taking, absence of renal and gastrointestinal involvement, and other drugs or disease-related causes. Clinical diagnosis of MSMD has been established according to the European Society for Immunodeficiencies criteria [17]. Genomic DNA extraction was performed using the whole peripheral blood sample. The whole-exome sequencing and confirmatory Sanger sequencing method were carried out according to a method published previously [18]. The literature search for reported MSMD patients was conducted in PubMed, Web of Science, and Scopus, applying the following keywords: "MSMD", "Mendelian susceptibility to mycobacterial disease", "Idiopathic infection caused by BCG or atypical mycobacteria", "Mendelian susceptibility to atypical mycobacteria", "Mendelian susceptibility to mycobacterial infections", in combination with subsequent terminology: "vasculitis", "Angiitis", "hypersensitivity vasculitis", "leukocytoclastic vasculitis". Reference lists of all full-text articles and major reviews were manually searched for additional studies. The descriptive and comparative section was then developed on patients with MSMD patients.

\section{Results \\ Case presentation}

Our patient was a 20-year-old Baluch female, born to consanguineous parents from Sistan and Baluchestan. The patient has been studied previously along with other patients with MSMD [19]. She had a familial history of childhood death in her father's cousins.

The proband was inoculated with bacillus CalmetteGuérin (BCG) at birth. She developed right axillary lymphadenitis at the age of 5 months following BCG vaccination and was treated with an anti-tuberculosis regimen for 3 months. At the age of 7 and 10 years old, she experienced recurrent cervical adenopathy and underwent lymph node excisional biopsy. The histopathology showed a reactive reaction with no sign of acidfast bacilli. Later, she was hospitalized for general lymphadenopathy with abdominal lymph involvement at 
the age of 11 years. Further investigation was made through laparotomy and lymph node biopsy, which was accordant with reactive reaction and she was treated with antimycobacterial drugs for six months. She was referred to our hospital at the age of 12-year-old with complaints of cervical mass and weight loss. She went through full clinical, laboratory, and histological investigations. On physical examination, her weight and height growths were in the 10th percentile. She had bilateral cervical and inguinal lymphadenopathy. There were palpable purpuric rashes on her both legs resembling leukocytoclastic vasculitis.

Her biochemical markers such as serum hepatic enzymes, activated partial thromboplastin time, and prothrombin time were within normal ranges. No proteinuria, hematuria, or impaired renal function was detected. Blood analysis revealed normochromic normocytic anemia and a high erythrocyte sedimentation rate $(125 \mathrm{~mm} /$ first hour). Immunological investigation revealed a slight reduction in lymphocyte subsets including CD4+, CD19+, and CD 16+56 T-cell counts compared to age-adjusted-values. Other than hypergammaglobulinemia, the complement levels and neutrophil functions (Nitro blue Tetrazolium) were unremarkable. A purified protein derivative (PPD) skin test and microscopy of sputum samples for acid-fast bacilli, polymerase chain reaction (PCR), and culture for detecting mycobacterium tuberculosis were done and the results were negative (Table 1). Serologic tests ruled out other possible underlying causes of vasculitis. The biopsy of the skin lesion showed neutrophil infiltration in the dermal vessel walls compatible with leukocytoclastic vasculitis.

The histopathologic examination of the lymph node showed chronic lymphadenitis without acid-fast bacilli. At the time, she was treated with isoniazid $(15 \mathrm{mg} / \mathrm{kg} /$ day), rifampin ( $10 \mathrm{mg} / \mathrm{kg} /$ day), ethambutol $(20 \mathrm{mg} / \mathrm{kg} /$ day), ciprofloxacin $(20 \mathrm{mg} / \mathrm{kg} /$ day), clarithromycin (15 $\mathrm{mg} / \mathrm{kg} /$ day $)$, and IFN-y $\left(50 \mu / \mathrm{m}^{2}\right.$ every other day) for nine months and her clinical statusimproved after the treatment. However, she experienced multiple recurrence of LCV afterwards. During followup, dapsone and clofazimine were added to her regimen for 6 months. She experienced recurrence of lymphadenopathy, therefore, rifampin, isoniazid and ofloxacin $(15 \mathrm{mg} / \mathrm{kg} /$ day $)$ were discontinued and replaced by prothionamide (15$20 \mathrm{mg} / \mathrm{kg} /$ day), cycloserine $(15-20 \mathrm{mg} / \mathrm{kg} /$ day), and later by levofloxacin $(15 \mathrm{mg} / \mathrm{kg} /$ day $)$, and fluvoxamine.

The patient relapsed at the age of 13 years and manifested right unilateral cervical lymph node enlargement. After cultivating the enlarged lymph node's sample, a tuberculosis-like complex was detected but PCR sequencing of the sample was accordant to M.Bovis. Given her clinical and laboratory data, she underwent whole-exon sequencing for possible IFN- $\gamma$ signaling pathway mutation. The genetic study identified a homozygous Indel-frameshift
Table 1 Immunologic profile of the index patient

\begin{tabular}{|c|c|c|}
\hline Parameters & Patient & Normal ranges \\
\hline 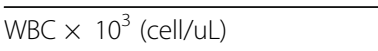 & 5.3 & $4.5-13.5$ \\
\hline Hemoglobin (g/dL) & 7.7 & $11.5-15.5$ \\
\hline Monocytes (cell/uL) & 0.5 & $0.2-0.8$ \\
\hline Lymphocytes (cell/uL) & 1.5 & $1.3-6.5$ \\
\hline Neutrophils (cell/uL) & 3.0 & $1.5-9.5$ \\
\hline $\mathrm{CD}^{+} \mathrm{T}$ cells (\% of lymphocytes) & $63.9 \%$ & 62.6-80.4 (\%) \\
\hline $\mathrm{CD}^{+} \mathrm{T}$ cells (\% of T cells) & $31.4 \%$ & $32.6-51.5(\%)$ \\
\hline $\mathrm{CD}^{+} \mathrm{T}$ cells (\% of T cells) & $20.8 \%$ & 19.0-29.0 (\%) \\
\hline CD $19^{+}$(\% of lymphocytes) & $6.9 \%$ & 11.9-21.0 (\%) \\
\hline CD $16^{+} 56^{+}$(\% of lymphocytes) & $12.3 \%$ & $4.3-16.2(\%)$ \\
\hline $\operatorname{lgG}(\mathrm{mg} / \mathrm{dL})$ & 2700 & $503-1719$ \\
\hline $\lg A(m g / d L)$ & 425 & $42-295$ \\
\hline $\operatorname{lgM}(\mathrm{mg} / \mathrm{dL})$ & 360 & $41-255$ \\
\hline $\operatorname{lgE}(I U / m L)$ & 100 & $<100$ \\
\hline ESR (mm/first hour) & 125 & $<17$ \\
\hline NBT (\%) & 99 & $>80$ \\
\hline C3 (IU/mL) & 110 & $88-206$ \\
\hline C4 (IU/mL) & 38 & $13-75$ \\
\hline CH50 (IU/mL) & 80 & $42-95$ \\
\hline $\mathrm{T}$ cell response to $\mathrm{BCG}$ & 1.9 & $>2.5$ \\
\hline T cell response to $\mathrm{PHA}$ & 3.1 & $\geq 3$ \\
\hline T cell response to Candida & - & $>2.5$ \\
\hline PPD & Negative & \\
\hline ANA & Negative & \\
\hline Anti-CCP & Negative & \\
\hline p-ANCA & Negative & \\
\hline C-ANCA & Negative & \\
\hline
\end{tabular}

Ig immunoglobulin, WBC white blood cell, ESR erythrocyte sedimentation rate, NBT Nitro blue tetrazolium, ANA antinuclear antibody, Anti-CCP anti-cyclic citrullinated peptide $\mathrm{CH} 50 ; 50 \%$ hemolytic complement activity, $\mathrm{PHA}$ phytohemagglutinin, $B C G$ Bacillus Calmette-Guérin, $P P D$ purified protein derivative, $p$-ANCA Perinuclear anti-neutrophil cytoplasmic antibodies, $c-A N C A$ Antineutrophil cytoplasmic antibodies

mutation, c.527_528delCT (p. S176Cfs"12), at the exon 5 of the $I L 12 B$ gene and due to the type of her mutation, she was not a candidate for hematopoietic stem cell transplantation (HSCT).

In her lastest visit, despite the resolvation of her other symptoms with rifampin, isoniazid, levofloxacin, cycloserine, amikacin, ethambutol, and IFN- $\gamma$, she still suffered from LCV.

\section{Literature review}

The literature search revealed 18 MSMD patients with vasculitis phenotype ( 9 females, 7 males, 2 unknown) with a median age of onset of $0.7(0.3-5.0)$ year and diagnosis of $6.0(3.0-10.0)$ year (Table 2). The most 
Sharifinejad et al. Pediatric Rheumatology

(2021) 19:121

Page 4 of 8

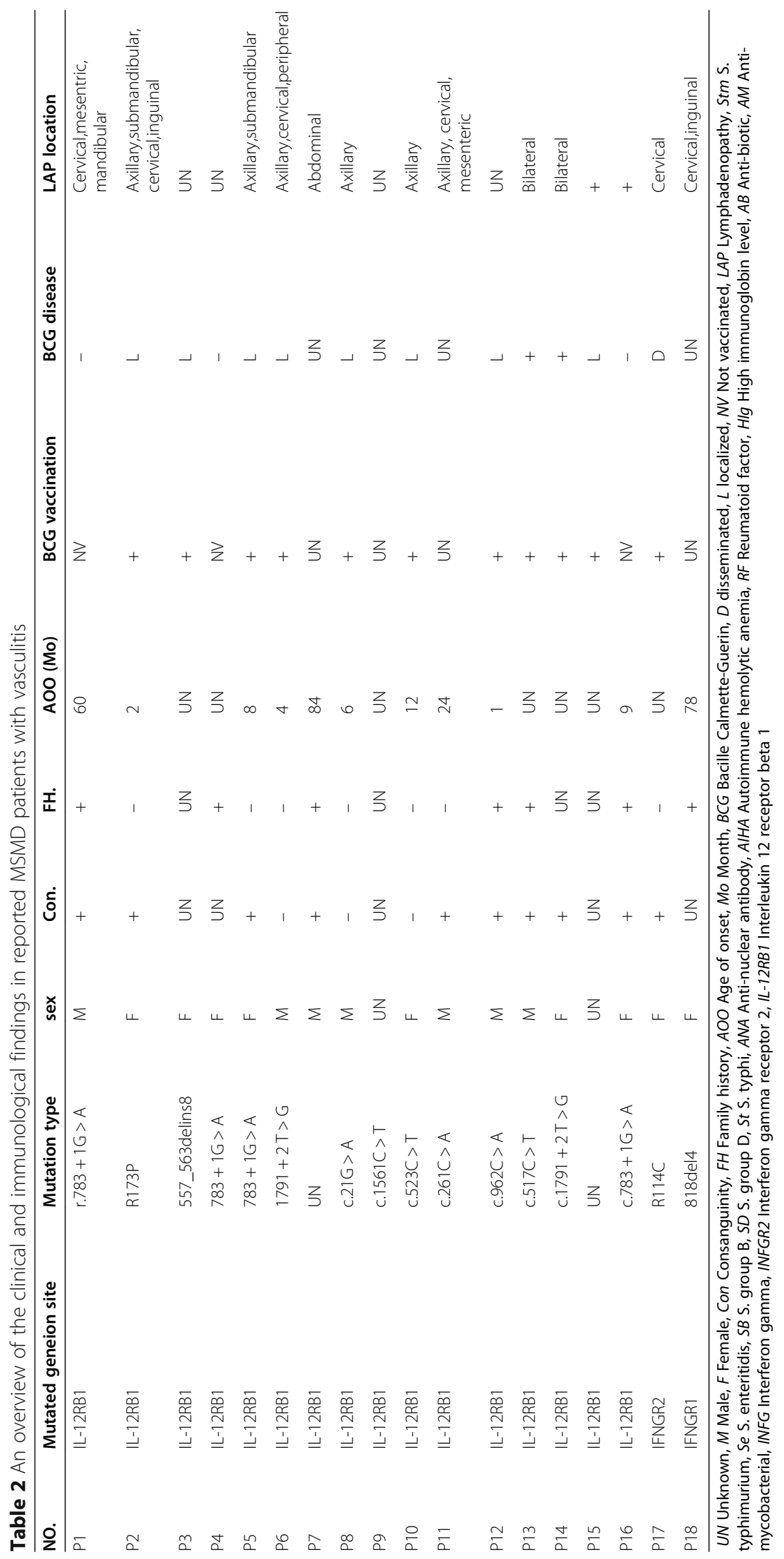




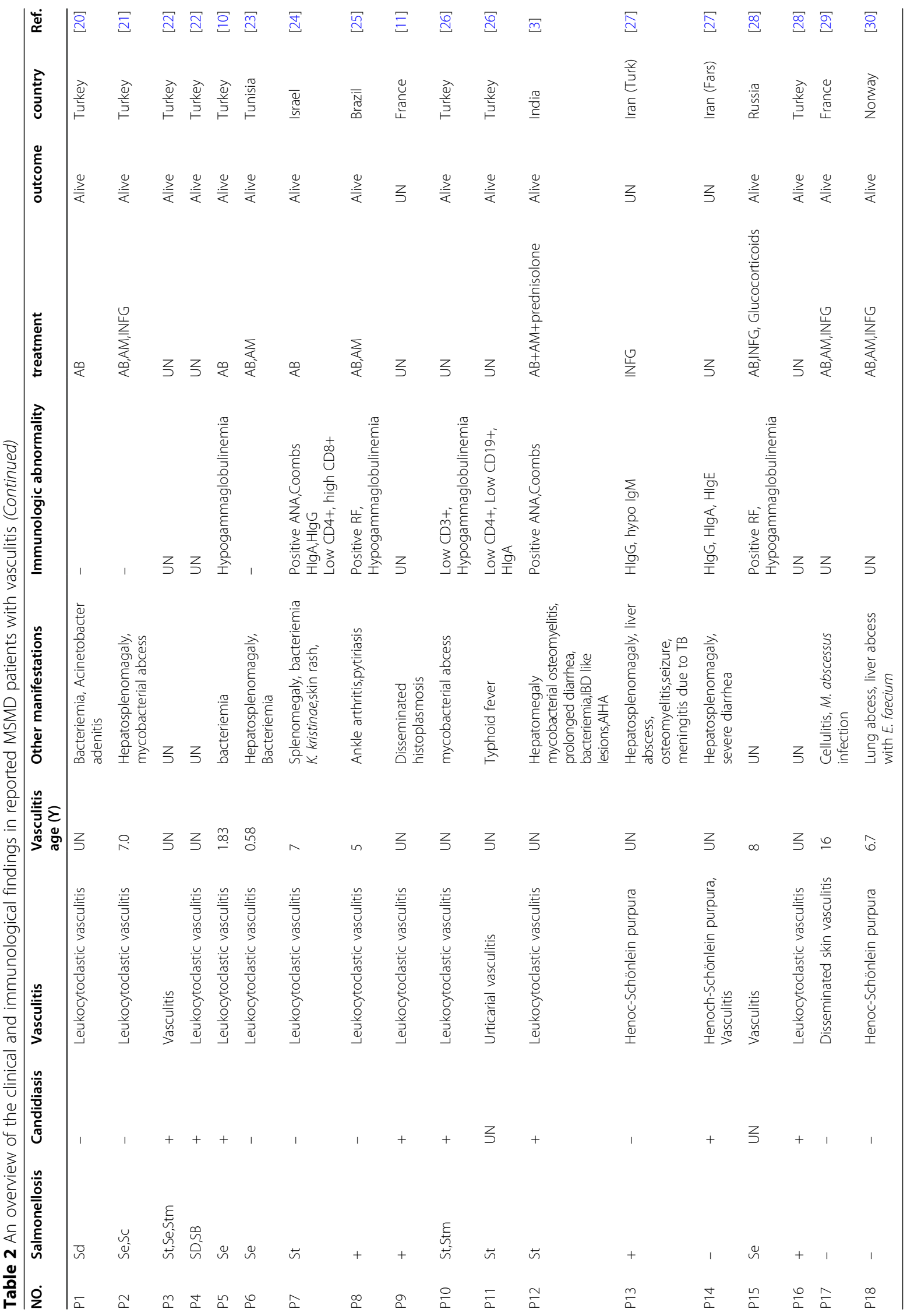


prevalent genetic defect in MSMD patients with vasculitis was $I L-12 R B 1$ (16 of $18,88.9 \%$ ). Most of the patients were from Turkey $44.4 \%$, followed by Iran and France (each 11.1\%). Consanguineous marriage was reported in $76.9 \%$ (10 of 13 with available data) of patients and $42.9 \%$ (6 of 14) patients had a positive family history of immunodeficiency (most with similar symptoms). Fifteen patients were alive during the median follow-up of 12.0 (6.7-18.2) years (the life status of three patients was not available). About $79 \%$ of patients (11 of 14 ) were vaccinated with BCG after birth and all of them developed BCG disease. However, only one patient presented with BCG-osis [29]. Patients were all reported to demonstrate vasculitis at the median age of $6.8(2.6-7.7)$ years. Lymphadenopathy was the main first clinical presentation and involved all patients with available data. Furthermore, hepatomegaly and splenomegaly each appeared in 5 (41.7\%) patients. Salmonellosis, as the most important concurrent infection in these patients, was detected in $88.2 \%$ (15 of 17). About half of patients (8 of 15) manifested candidiasis as well.

The normal immunological parameters were the most reported results in MSMD patients with vasculitis. Moreover, high IgG, high IgA, and high IgM were detected in $72.7 \%$ ( 8 of 11 ), $72.7 \%$ (8 of 11 ), and $45.5 \%$ (5 of 11) of the patients. Anti-mycobacterial agents were the most supportive treatments and 5 patients underwent IFN- $\gamma$ therapy. All patients treated with IFN- $\gamma$, are alive and achieved resolution of major symptoms.

\section{Discussion}

MSMD is an early-onset primary immunodeficiency that mainly presents mycobacterial lymphadenitis [5]. Here, we described a 20-year-old Iranian female presented with a homozygous mutation, c.527_528delCT (p. S176Cfs*12) of the $I L 12 B$ gene. She suffered from recurrent lymphadenitis since infancy and later manifested LCV. As opposed to most patients with LCV [4, 10, 23], Salmonella species were not isolated from our patient and she did not experience candidiasis either. She is the second patient with IL-12B/RB deficiency manifested with LCV without Salmonella infection. Most of the reported MSMD patients with vasculitis $(n=16,88.9 \%)$ had IL12RB1 defects, and concurrent Salmonella infection was reported in 15 (88.2\%) patients as IL-12 pathway is involved during Salmonella infection [15]. Moreover, LCV in MSMD patients predominantly presented with palpable purpuric rashes located on lower extrimities and were compeletly resolved following the use of 3rd generation cephalosporins as part of the anti-tuberculosis regimen, ciprofloxacin alone or in combination with INF- $\gamma[10,21,23,24]$, further strengthening the possible role of salmonella infection in the development of LCV. Subacute salmonellosis or lack of appropriate follow-up might be the reason of not detecting
Salmonella species in some cases. Therefore, the lack of IL12 and IL-23 immunity and salmonella infection may be triggering factors for the development of vasculitis. However, our patient as an outlier, experienced recurrent episodes of LCV that did not relieve even after the resolvation of her other symptoms or treating with anti-tuberculosis and anti-salmonella drugs.

Laboratory analysis detected positive RF and a slight decrease in CD4+, CD19+, and CD $16+56$ T-cell count. Döffinger et al. have also reported an IFNGR2-deficient patient presented with vasculitis but no sign of Salmonella or Candida infections [29]. Similar to Kutukculer N et al., our patient did not achieve symptom resolution before the initiation of IFN- $\gamma$ therapy [21].

Vasculitis is a phenomenon that could be associated with infection, autoimmune and inflammatory conditions including medications. Various infectious agents can cause vasculitis directly or clinically mimicking primary vasculitis [31]. Hypersensitivity vasculitis is a rare manifestation occurring during an atypical mycobacterial infection in a healthy subject [32, 33]. Furthermore, there are a few exceptional MSMD-deficient patients that presented with $\mathrm{LCV}$, especially patients with $I L$ $12 R \beta 1$ deficiency $[3,26,27]$. Our review of 18 MSMD cases with vasculitis revealed that this complication appears in middle childhood in patients predominantly originated from Turkey. Since Th1 is involved in ANCA-associated vasculitis and a majority of patients with MSMD developed Henoc-Schönlein purpura or $\mathrm{LCV}$, the etiology of vasculitis in MSMD might not be Th1-mediated [34]. Noteworthy, most patients were positive for Salmonella species, suggesting an association for vasculitis and salmonellosis in the cases. On the other hand, it is possible that subclinical Salmonella infections or lack of appropriate follow-up in patients are the underlying reasons for negative Salmonella isolation in some cases. Candidiasis was also common among the reviewed patients, however, most of our reported patients had $I L-12 R B$ deficiency and this mutation is previously known to positively correlate with candidiasis [5]. As expected, laboratory data were predominantly normal including lymphocyte subsets, however, most patients were detected with hyperimmunoglobulinemia. BCG vaccination seems to be an important factor as all vaccinated patients developed BCG disease. Therefore, investigating the family history of abnormal post-vaccination complications or atypical mycobacterial infections before BCG administration would benefit MSMD patients with susceptibility to infection with weakly virulent mycobacteria.

\section{Conclusion}

In conclusion, cutaneous vasculitis in MSMD patients could be pathognomic of an underlying IL12B or IL12R $\beta 1$ deficiency, particularly in those complicated with 
Salmonella infections. Furthermore, although vasculitis is a relatively late symptom, clinicians should be aware of possible underlying causes of cutaneous vasculitis in children presenting with unusual recurrent Salmonella and weakly virulent mycobacteria infections and investigate for possible IFN- $\gamma$ pathway mutations.

\section{Abbreviations}

MSMD: Mendelian susceptibility to mycobacterial disease; BCG: Bacillus Calmette-Guérin; LCV: Leukocytoclastic vasculitis; HSP: Henoch-Schönlein purpura; IEl: Inborn error of immunity; PPD: Purified protein derivative; PCR: Polymerase chain reaction; HSCT: Hematopoietic stem cell transplantation

\section{Acknowledgements}

None.

\section{Authors' contributions}

NS; the acquisition, analysis, interpretation of data, and have drafted the work or substantively revised it, SM; have made substantial contributions to the conception, design of the work, substantively revised the work, MJ; have made substantial contributions to the conception, have drafted the work or substantively revised it, ZD; have drafted the work or substantively revised it, AM; have drafted the work or substantively revised it, MM; have drafted the work or substantively revised it, PT; have drafted the work or substantively revised it, PF; have drafted the work or substantively revised it, MR; have drafted the work or substantively revised it, MF; have drafted the work or substantively revised it, $\mathrm{SH}$; have drafted the work or substantively revised it, $\mathrm{MM}$; have drafted the work or substantively revised it, JB; design of the work, have substantively revised the work, JLC; design of the work, have substantively revised the work, DM; substantively revised the work, AV; substantively revised the work. All authors read and approved the final manuscript.

\section{Funding}

The authors received no specific funding for this research.

\section{Availability of data and materials}

All data generated or analysed during this study are included in this published article.

\section{Declarations}

\section{Ethics approval and consent to participate}

Not applicable.

\section{Consent for publication}

Informed consent was obtained from the parents of the patient prior to being included in the study.

\section{Competing interests}

The authors declare that they have no competing interests.

\section{Author details}

${ }^{1}$ Non-Communicable Diseases Research Center, Alborz University of Medical Sciences, Karaj, Iran. ${ }^{2}$ Pediatric Respiratory Diseases Research Center, National Research Institute of Tuberculosis and Lung Diseases (NRITLD), Shahid Beheshti University of Medical Sciences, Tehran, Iran. ${ }^{3}$ Pediatric Nephrology Research Center, Research Institute for Children's Health, Shahid Beheshti University of Medical Sciences, Tehran, Iran. ${ }^{4}$ Pediatric Infections Research Center, Research Institute for Children's Health, Shahid Beheshti University of Medical Sciences, Tehran, Iran. ${ }^{5}$ Clinical Tuberculosis and Epidemiology Research Centre, National Research Institute of Tuberculosis and Lung Diseases (NRITLD), Shahid Beheshti University of Medical Sciences, Tehran, Iran. ${ }^{6}$ Mycobacteriology Research Centre (MRC), National Research Institute of Tuberculosis and Lung Diseases (NRITLD), Shahid Beheshti University of Medical Sciences, Tehran, Iran. 'Laboratory of Human Genetics of Infectious Diseases, Necker Branch, INSERM UMR 1163, Necker Hospital for Sick Children, University of Paris, Imagine Institute, 75015 Paris, EU, France. ${ }^{8}$ St. Giles Laboratory of Human Genetics of Infectious Diseases, Rockefeller Branch, The Rockefeller University, New York, NY, USA. ${ }^{9}$ Center for the Study of Primary Immunodeficiencies, Necker Hospital for Sick Children, AP-HP, Paris, EU, France. ${ }^{10}$ Howard Hughes Medical Institute, New York, NY, USA.

Received: 19 April 2021 Accepted: 24 June 2021

Published online: 13 August 2021

\section{References}

1. Altare F, Durandy A, Lammas D, Emile JF, Lamhamedi S, Le Deist F, et al. Impairment of mycobacterial immunity in human interleukin-12 receptor deficiency. Science. 1998;280(5368):1432-5. https://doi.org/10.1126/science.2 80.5368.1432

2. Rosain J, Kong XF, Martinez-Barricarte R, Oleaga-Quintas C, Ramirez-Alejo N, Markle J, et al. Mendelian susceptibility to mycobacterial disease: 2014-2018 update. Immunol Cell Biol. 2019;97(4):360-7. https://doi.org/10.1111/ imcb. 12210

3. Jindal AK, Suri D, Guleria S, Rawat A, Garg S, Bal A, et al. Recurrent Salmonella typhi infection and autoimmunity in a young boy with complete IL-12 receptor $\beta 1$ deficiency. J Clin Immunol. 2019;39(4):358-62. https://doi.org/10.1007/s10875-019-00637-0.

4. Sanal O, Turul T, De Boer T, Van de Vosse E, Yalcin I, Tezcan I, et al. Presentation of interleukin-12/-23 receptor beta1 deficiency with various clinical symptoms of Salmonella infections. J Clin Immunol. 2006;26(1):1-6. https://doi.org/10.1007/s10875-006-7830-3.

5. Bustamante J. Mendelian susceptibility to mycobacterial disease: recent discoveries. Hum Genet. 2020;139(6-7):993-1000. https://doi.org/10.1007/ s00439-020-02120-y.

6. Yang R, Mele F, Worley L, Langlais D, Rosain J, Benhsaien I, et al. Human Tbet Governs Innate and Innate-like Adaptive IFN- $\gamma$ Immunity against Mycobacteria. Cell. 2020;183:1826-1847.e1831.

7. Le Voyer T, Neehus A-L, Yang R, Ogishi M, Rosain J, Alroqi F, et al. Inherited deficiency of stress granule ZNFX1 in patients with monocytosis and mycobacterial disease. Proc Natl Acad Sci. 2021;118(15):e2102804118. https://doi.org/10.1073/pnas.2102804118.

8. Nathan CF, Murray HW, Wiebe ME, Rubin BY. Identification of interferongamma as the lymphokine that activates human macrophage oxidative metabolism and antimicrobial activity. J Exp Med. 1983;158(3):670-89. https://doi.org/10.1084/jem.158.3.670.

9. Chen KR, Carlson JA. Clinical approach to cutaneous vasculitis. Am J Clin Dermatol. 2008;9(2):71-92. https://doi.org/10.2165/00128071-20080902000001.

10. Filiz S, Kocacik Uygun DF, Verhard EM, Van Dissel JT, Uygun V, Bassorgun C, et al. Cutaneous leukocytoclastic vasculitis due to Salmonella enteritidis in a child with interleukin-12 receptor beta-1 deficiency. 2014;31:236-40.

11. Rosain J, Oleaga-Quintas C, Deswarte C, Verdin H, Marot S, Syridou G, et al. A variety of Alu-mediated copy number variations can underlie IL-12Rß1 deficiency. J Clin Immunol. 2018;38(5):617-27. https://doi.org/10.1007/s1 0875-018-0527-6.

12. Parham C, Chirica M, Timans J, Vaisberg E, Travis M, Cheung J, et al. A receptor for the heterodimeric cytokine IL-23 is composed of IL-12Rbeta1 and a novel cytokine receptor subunit, IL-23R. J Immunol. 2002;168(11): 5699-708. https://doi.org/10.4049/jimmunol.168.11.5699.

13. de Beaucoudrey L, Puel A, Filipe-Santos O, Cobat A, Ghandil P, Chrabieh M, et al. Mutations in STAT3 and IL12RB1 impair the development of human IL-17-producing T cells. J Exp Med. 2008;205(7):1543-50. https://doi.org/10.1 084/jem.20080321.

14. Powell MD, Read KA, Sreekumar BK, Jones DM, Oestreich KJ. IL-12 signaling drives the differentiation and function of a TH1-derived TFH1-like cell population. Sci Rep. 2019;9(1):13991. https://doi.org/10.1038/s41598-01950614-1.

15. Mizuno $Y$, Takada $\mathrm{H}$, Nomura $\mathrm{A}$, Jin $\mathrm{CH}$, Hattori $\mathrm{H}$, Ihara $\mathrm{K}$, et al. Th1 and Th1-inducing cytokines in Salmonella infection. Clin Exp Immunol. 2003; 131(1):111-7. https://doi.org/10.1046/j.1365-2249.2003.02060.x.

16. Abolhassani H, Tavakol M, Chavoshzadeh Z, Mahdaviani SA, Momen T, Yazdani $R$, et al. National consensus on diagnosis and management guidelines for primary immunodeficiency. Immunol Genet J. 2019;2:1-21.

17. Seidel MG, Kindle G, Gathmann B, Quinti I, Buckland M, van Montfrans J, et al. The European Society for Immunodeficiencies (ESID) registry working definitions for the clinical diagnosis of inborn errors of immunity. J Allergy Clin Immunol Pract. 2019;7(6):1763-70. https://doi. org/10.1016/j.jaip.2019.02.004. 
18. Fang M, Abolhassani H, Lim CK, Zhang J, Hammarstrom L. Next generation sequencing data analysis in primary immunodeficiency disorders - future directions. J Clin Immunol. 2016;36(Suppl 1):68-75. https://doi.org/10.1007/ s10875-016-0260-y.

19. Mahdaviani SA, Mansouri D, Jamee M, Zaki-Dizaji M, Aghdam KR, Mortaz E, et al. Mendelian susceptibility to mycobacterial disease (MSMD): clinical and genetic features of 32 Iranian patients. J Clin Immunol. 2020;40(6):872-82. https://doi.org/10.1007/s10875-020-00813-7.

20. Sanal O, Turul T, De Boer T, Van De Vosse E, Yalcin I, Tezcan I, et al. Presentation of interleukin-12/-23 receptor $\beta 1$ deficiency with various clinical symptoms of salmonella infections. 2006;26:1-6.

21. Kutukculer N, Genel F, Aksu G, Karapinar B, Ozturk C, Cavusoglu C, et al. Cutaneous leukocytoclastic vasculitis in a child with interleukin-12 receptor beta-1 deficiency. J Pediatr. 2006;148(3):407-9. https://doi.org/10.1016/j. jpeds.2005.10.003

22. de Beaucoudrey L, Samarina A, Bustamante J, Cobat A, Boisson-Dupuis S, Feinberg J, et al. Revisiting human IL-12RB1 deficiency: a survey of 141 patients from 30 countries. Medicine (Baltimore). 2010;89(6):381-402. https://doi.org/10.1097/MD.0b013e3181fdd832.

23. Khamassi I, Ben Ali M, Ben Mustapha I, Barbouche MR, Bejaoui M, Bouyahia $\mathrm{O}$, et al. Salmonella enteriditis inducing cutaneous leucocytoclasic vasculitis: an unusual complication in a patient with an interleukine- 12 receptor beta1 deficiency. Tunis Med. 2015;93(5):328-9.

24. Mandola A, Broides A, Nahum A. Salmonella typhi infection causing prolonged chronic illness and cutaneous leucocytoclastic vasculitis in a patient with IL 12 receptor $\beta-1$ deficiency. LymphoSign Journal. 2016. https://doi.org/10.14785/lymphosign-2016-0013.

25. Louvain de Souza T, de Souza Campos Fernandes RC, Azevedo da Silva J, Gomes Alves Júnior V, Gomes Coelho A, Souza Faria AC, et al. Microbial Disease Spectrum Linked to a Novel IL-12Rß1 N-Terminal Signal Peptide Stop-Gain Homozygous Mutation with Paradoxical Receptor Cell-Surface Expression. Front Microbiol. 2017;8:616-6.

26. Doğruel D, Gündeșlioğlu Ö, Yılmaz M, Alabaz D, Alııntaş DU, Kocabaş E. Clinical findings and genetic analysis of the patients with IL-12Rß1 deficiency from Southeast Turkey. Turk J Pediatr. 2019;61(2):174-9. https:// doi.org/10.24953/turkjped.2019.02.004

27. Sarrafzadeh SA, Nourizadeh M, Mahloojirad M, Fazlollahi MR, Shokouhi Shoormasti R, Badalzadeh M, et al. Molecular, immunological, and clinical features of 16 Iranian patients with Mendelian susceptibility to mycobacterial disease. J Clin Immunol. 2019;39(3):287-97. https://doi.org/1 0.1007/s10875-019-0593-4

28. Kozlova A, Zinovieva N, Bustamante J, Boisson-Dupuis S, Casanova JL, Shcherbina A. P03-025 - differential diagnosis of autoimmune disorders. Pediatr Rheumatol. 2013;11(S1):A223. https://doi.org/10.1186/1546-0096-11-S1-A223.

29. Döffinger R, Jouanguy E, Dupuis S, Fondanèche MC, Stephan JL, Emile JF, et al. Partial interferon-gamma receptor signaling chain deficiency in a patient with bacille Calmette-Guérin and mycobacterium abscessus infection. J Infect Dis. 2000:181(1):379-84. https://doi.org/10.1086/315197.

30. Glosli H, Stray-Pedersen A, Brun AC, Holtmon LW, Tønjum T, Chapgier A, et al. Infections due to various atypical mycobacteria in a Norwegian multiplex family with dominant interferon-gamma receptor deficiency. Clin Infect Dis. 2008;46(3):e23-7. https://doi.org/10.1086/525855.

31. Somer T, Finegold SM. Vasculitides associated with infections, immunization, and antimicrobial drugs. Clin Infect Dis. 1995;20(4):1010-36. https://doi.org/1 0.1093/clinids/20.4.1010

32. Touma Z, Haddad A, Gladman DD, Uleryk EM, Urowitz MB. Skin nontuberculous mycobacterial infection in systemic lupus erythematosus: an unusual skin infection mimicking lupus vasculitis. Semin Arthritis Rheum. 2013:42(5):498-506. https://doi.org/10.1016/j.semarthrit.2012.08.002.

33. Walsh TL, Baca V, Stalling SS, Natalie AA, Veldkamp PJ. Mycobacterium avium-intracellulare pulmonary infection complicated by cutaneous leukocytoclastic vasculitis in a woman with anorexia nervosa. Infection. 2014;42(3):559-63. https://doi.org/10.1007/s15010-013-0574-0.

34. Martinez Valenzuela L, Bordignon Draibe J, Fulladosa Oliveras X, Bestard Matamoros O, Cruzado Garrit JM, Torras Ambrós J. T-lymphocyte in ANCAassociated vasculitis: what do we know? A pathophysiological and therapeutic approach. Clin Kidney J. 2019;12(4):503-11. https://doi.org/10.1093/ckj/sfz029.

\section{Publisher's Note}

Springer Nature remains neutral with regard to jurisdictional claims in published maps and institutional affiliations.

Ready to submit your research? Choose BMC and benefit from:

- fast, convenient online submission

- thorough peer review by experienced researchers in your field

- rapid publication on acceptance

- support for research data, including large and complex data types

- gold Open Access which fosters wider collaboration and increased citations

- maximum visibility for your research: over $100 \mathrm{M}$ website views per year

At BMC, research is always in progress.

Learn more biomedcentral.com/submissions 